- the letter of the law but well outside the spirit of the law". The moratorium inevitably reflects ethical objections to breeding, he argues, not just its costs. Requiring the NIRC to take responsibility for offspring of federally owned chimps is a reasonable way to cover accidental births due to the failure of contraceptive methods, but it should not be taken as a licence to breed, he adds.

Rowell says that the NIRC has taken several measures to reduce the number of animals being born compared with when it was "in a breeding mode" before 1995. Then, 20-40 births per year were typical. The measures include the use of intrauterine devices in females; discontinuing immediate weaning of offspring, so that females remain infertile for up to four years after giving birth; vasectomizing selected males; and housing males and females separately where possible.

But because of the importance of maintaining breeding capacity in case the moratorium is lifted, Rowell says, the centre chose not to sterilize all animals. "The NIRC has made a good-faith attempt to maintain our colony as a high-value resource for both immediate and future need to the biomedical research community," he says. "The additional animals play a pivotal role in addressing global human health problems."

Although the NIH states that the moratorium was instituted for economic reasons, "more and more people are becoming conscious of the fact that chimps in research suffer in horrible ways that we don't want them to be suffering," says Bruce Wagman, a partner and animal-law expert in the San Francisco office of the law firm Schiff Hardin.

In mid-December, a committee of the US Institute of Medicine is due to opine on whether the NIH should continue to fund chimp research at all. The NIH called for the study after strong protests against its efforts to move 186 semi-retired chimpanzees back into active research (see Nature 467, 507-508; 2010).

Paradoxically, the NIH has benefited from the continued breeding of federal animals. The agency's National Institute of Allergy and Infectious Diseases has paid the Louisiana centre more than $\$ 6$ million since 2002 to provide it with 4 to 12 infant chimpanzees annually for studies of hepatitis $\mathrm{C}$ and other viral diseases. According to the data gathered by the Humane Society, 50 of these chimps were born to one or more $\mathrm{NIH}$-owned animals.

"Rather than passing off the costs and therefore saying 'it's no problem', the NIH should be doing everything it can to enforce the breeding moratorium," says Wagman. "The moratorium is absolute." SEE EDITORIALP.445

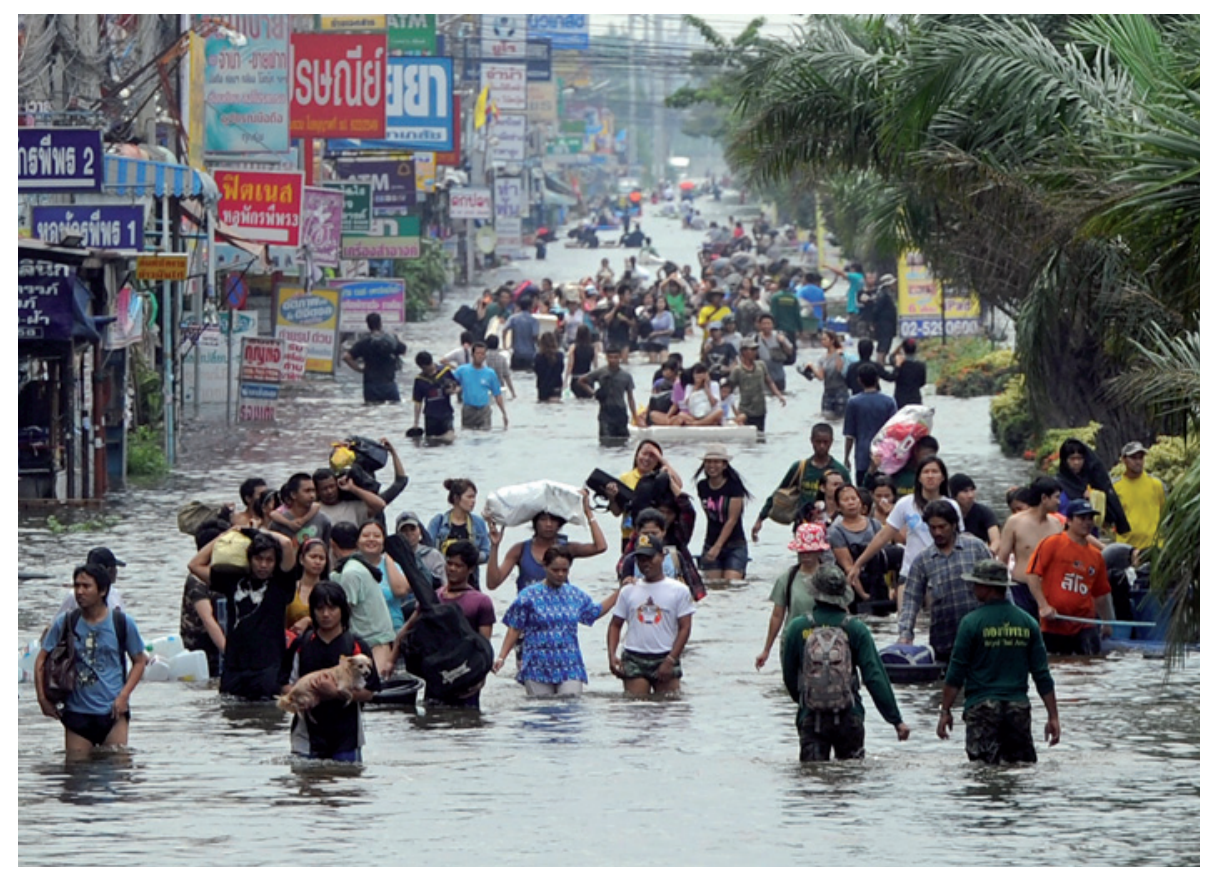

Nations that are vulnerable to flooding and drought stand to lose out if climate talks fail.

CLIMATE POLICY

\title{
Showdown nears for climate deal
}

\author{
Expected debate over Kyoto Protocol threatens to stall \\ progress on other fronts.
}

\section{BY JEFF TOLLEFSON}

$\mathrm{T}$ There's a storm brewing in South Africa, although not the kind that climate scientists warned of last week in a report linking extreme weather to global warming (see http://dx.doi. org/10.1038/nature.2011.9397; 2011). This one is the political tempest that is swirling around the Kyoto Protocol. Forecasts suggest that it will hit in full force when delegates to the seventeenth meeting of the United Nations Framework Convention on Climate Change gather in Durban on 28 November - and it could threaten progress on an alternative agreement.

Negotiated in 1997, Kyoto combines commitments by wealthy nations (excluding the United States, which has never ratified the agreement) to limit greenhouse-gas emissions with monetary and technical support for poor nations. The commitments are set to expire next year and nothing comparable has materialized to take their place.

The world has changed since Kyoto was negotiated. Powerhouse developing economies are now among the world's leading

carbon dioxide emitters. Today, China holds the number one spot and India is fourth behind the United States and the European Union (EU). With Western nations in the midst of a financial crisis, there is little enthusiasm for renewing Kyoto, or for the underlying assumption that the developed world should shoulder the full burden of controlling greenhouse-gas emissions. In Durban, supporters of Kyoto - mainly developing nations - will make their last stand.

"The world can't punt this issue any longer," says Robert Stavins, an environmental economist at Harvard University's John F. Kennedy School of Government in Cambridge, Massachusetts. Stavins believes that negotiators will find some way to keep the Kyoto Protocol alive, if only in spirit, but he acknowledges that the meeting could also fall apart. "Some people would say that this is the death that is required

D NATURE.COM Read a Comment on the future of the Kyoto Protocol: go.nature.com/c3zfk2 in order to have a rebirth" in the negotiating process, he says.

Cracks began to show in the framework's political underpinnings two 
years ago in Copenhagen (see Nature 462, 966967; 2009), when world leaders first broke with the Kyoto formula to offer the developing world rewards without commitments. Japan, Canada and Russia, which all agreed to the original protocol, said that they opposed a second commitment period. Even the EU may not support an extension of Kyoto, Stavins says, although its trail-blazing carbon trading system could continue even if the treaty becomes dormant.

In Copenhagen, and again last year in Cancún, Mexico, countries such as China, Brazil and South Africa joined wealthy nations in making voluntary commitments to limit emissions of greenhouse gases. In exchange, wealthy countries agreed to ramp up financing to help the poorest countries prepare for global warming. The framework that emerged is more inclusive than Kyoto, but lacks the formal stature of a fully binding international treaty. Developing countries, as a bloc, are reluctant give up on the old protocol until something more concrete takes its place.

"The call to mandate a new treaty in place of the Kyoto Protocol should be understood for what it is - rich countries backtracking on inconvenient commitments, at the expense of the poor and the planet," says Lim Li Lin, who works with developing countries at the Third World Network, a non-profit advocacy group based in Penang, Malaysia.

Under the Copenhagen Accord, countries agreed to try to limit global warming to $2^{\circ} \mathrm{C}$ and to consider lowering that target to $1.5^{\circ} \mathrm{C}$. Actual commitments to greenhouse-gas cuts fell well short of what studies suggest are needed to meet the $2{ }^{\circ} \mathrm{C}$ goal. The accord also includes provisions to slow deforestation, promote adaptation and hasten the spread of green technologies, with wealthy countries promising US $\$ 30$ billion in financing by 2012 , which will increase to $\$ 100$ billion annually by 2020 .

Negotiators were able to advance many of these initiatives in Cancún last year, but crucial details regarding which institutions will manage this money, who will decide how it is spent and how emissions commitments will be registered and tracked remain unresolved. "Durban needs to put the entire architecture of climate-resilient development on a more solid basis," says Koko Warner, a climate policy expert with the United Nations University Institute for Environment and Human Security in Bonn, Germany.

But many fear that frustration over Kyoto could stall progress in other areas of the talks and threaten the viability of the Copenhagen Accord.

"I think what really kept developing countries at the negotiating table in Copenhagen was the $\$ 100$ billion per year," says Timmons Roberts, who heads the Center for Environmental Studies at Brown University in Providence, Rhode Island. "If it's just another empty aid promise, the Copenhagen Accord is going to fall apart." -

\section{FUNDING}

US science agencies
dodge deep cuts

\section{Partial 2012 budget mostly spares research, but deficit- reduction measures still pose a looming threat.}

\section{BY IVAN SEMENIUK}

$\mathrm{T}$ he most fractious and combative US Congress in recent memory is getting on with approving a 2012 budget although perhaps only so that it can move more swiftly to the next battlefield. On 17 November, legislators passed a spending bill that includes allocations for several key science-related agencies. The bill has since been signed off by President Barack Obama.

The budget was a relief for researchers and their advocates, who had feared deeper cuts to science. Under the provisions of the bill, the National Science Foundation (NSF), the National Oceanic and Atmospheric Administration (NOAA), the National Institute of Standards and Technology and the Food and Drug Administration (FDA) all received modest increases (see table).

Even NASA, which has seen its budget shrink by nearly US $\$ 1$ billion over the past two years - essentially because it has ended the space-shuttle programme - kept all its major science initiatives. It even got an increase for the 6.5-metre James Webb Space Telescope (JWST), which has been subject to chronic cost overruns that at one point prompted deficit-focused Republicans to propose dropping it from the space agency's budget altogether.

"That wakes you up," says Kevin Marvel, executive officer of the American Astronomical Society in Washington DC. The JWST has now been restored, with continued support endorsed by both the House of Representatives and the Senate, and NASA's science budget has increased by $3.1 \%$. Although this by no means solves all of NASA's budget woes - the agency is also facing questions about a series of missions to Mars (see Editorial, page 446 ) - it is a reassuring outcome in financially uncertain times. "Compared to where we could have been, we are in a good place for 2012," says Marvel.

The NSF is also cautiously optimistic: its budget grew unexpectedly by almost US\$200 million dollars to just over \$7 billion. However, this falls short of the nearly $\$ 7.8$ billion that Obama requested for the NSF in February. That amount would have helped to maintain a ten-year

doubling of funding for the agency, as set out by the America COMPETES Act that was reauthorized last year.

The budget "lifts a huge cloud that was hanging over the agency and makes it into a much smaller one", says Michael Lubell, director of public affairs for the American Physical Society in Washington DC. Having used economic-stimulus money to increase funding to researchers in 2009-10, the NSF was already expecting to scale back its grants next year. The 2012 budget is not large enough to avoid that altogether, but the agency should be able to maintain its commitments to major research facilities while seeing a smaller reduction in grant-acceptance rates.

The FDA received a $\$ 50$-million increase in its congressional appropriation, \$39 million of which will go towards implementing a food-safety law passed in January. "It's good that they saw

"Compared to where we could have been, we're in a good place for 2012." the need to pass that funding, but we would like to have seen more," says David Plunkett, a senior staff attorney at the Center for Science in the Public Interest, an advocacy group in Washington DC. The FDA had estimated that it would need more than $\$ 183$ million in extra funding in 2012 to implement the food-safety act.

The spending bill holds both victories and disappointments for NOAA. The agency's budget will increase, with an allocation of $\$ 924$ million to continue funding its Joint Polar Satellite System — a programme with a history of budget problems, but one that politicians are reluctant to attack because its data are crucial for forecasting severe weather. Not so fortunate was an effort to combine a series of government functions in a national climate service, a stated goal of Jane Lubchenco, who was appointed as NOAA director by Obama in 2009. With climate science a favourite target of Republican ire, the proposed service $\rightarrow$ NATURE.COM For more on the US budget crisis, see: go.nature.com/eg2noo was turned down.

Another Obama appointee who is feeling the wrath of the right is John 